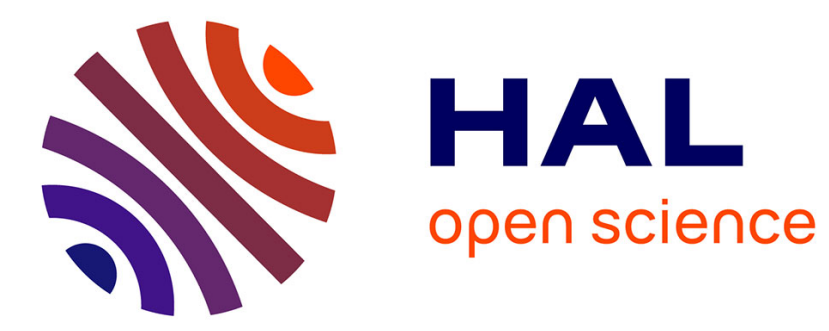

\title{
Revisiting the system of English relative clauses: structure, semantics, discourse functionality
}

Francis Cornish

\section{To cite this version:}

Francis Cornish. Revisiting the system of English relative clauses: structure, semantics, discourse functionality. English Language and Linguistics, 2018, 22, pp.431 - 456. hal-01923355

\section{HAL Id: hal-01923355 \\ https://hal-univ-tlse2.archives-ouvertes.fr/hal-01923355}

Submitted on 15 Nov 2018

HAL is a multi-disciplinary open access archive for the deposit and dissemination of scientific research documents, whether they are published or not. The documents may come from teaching and research institutions in France or abroad, or from public or private research centers.
L'archive ouverte pluridisciplinaire HAL, est destinée au dépôt et à la diffusion de documents scientifiques de niveau recherche, publiés ou non, émanant des établissements d'enseignement et de recherche français ou étrangers, des laboratoires publics ou privés. 
(Article published in English Language and Linguistics 22(3), pp. 431-456, November 2018)

\title{
Revisiting the system of English relative clauses: structure, semantics, discourse functionality ${ }^{1}$
}

\author{
FRANCIS CORNISH
}

CLLE-ERSS UMR 5263 and Université de Toulouse-Jean Jaurès

\begin{abstract}
The goal of this article is to uncover the system underlying three types of English relative clauses, and to characterise their distinctive uses in discourse: NP-integrated ones, namely restrictive and 'a-restrictive' relative clauses, and non-integrated ones, represented by non-restrictive relatives.

The area at issue is central, since understanding the functioning of these constructions requires reference to the fundamental interface between grammar (language system) and discourse (language use). The discourse functions of the three subtypes of relatives are claimed to be underlain by their intrinsic morphosyntactic and semantic properties. A major aim is to highlight the relative degree of "communicative dynamism' of each subtype of relative clause, in terms of its respective contribution to the construction of discourse

In doing so, the article focuses on the distinctive properties of presupposed as well as non-presupposed restrictive relatives, and of definite as well as indefinite NPs containing integrated relatives more generally. Along the way, it critically examines certain controversial conceptions of the structural and functional features of the constructions at issue, and, in particular, the claim that there is no essential distinction to be drawn between 'integrated' and phrase-external relative clause subtypes at all.
\end{abstract}

Keywords: Relative clauses; A-restrictive relatives; Presupposed vs. non-presupposed relatives; Communicative dynamism; Discourse functionality

\footnotetext{
I would like to thank Jim Miller, Georges Kleiber, Daniel García Velasco, Fabio Del Prete and Ming-Ming Pu for their helpful comments on earlier drafts of this article, as well as the two anonymous ELL reviewers for their remarks on the initial submission, and in particular Bernd Kortmann.
} 


\section{INTRODUCTION}

A close study of the internal structure and use of restrictive (RRCs), 'A-RESTRICTIVE' (ARRCs) and non-restrictive relative clauses (NRRCs), is particularly worthwhile for the insights it yields into the relationship between grammar and discourse. The field of embedded subordinate clauses (here ARRCs and RRCs - both NP-integrated) in contrast to nonembedded ones - NRRCs - offers a rich panoply of types of linguistic structures and processes that are crucially involved in their structure as well as functioning. As we shall see, it is their structural and semantic properties that underpin and reflect their specific discourse functionality. A major aim of this article is to highlight the range of contributions made by the subtypes of relative clause at issue to the construction of discourse - that is, their relative degrees of 'communicative dynamism'.

The article is organised as follows. Section 2 is devoted to a characterization of the structural properties of the three subtypes of RCs at issue: in particular, the important distinction between clause introducers and relativized variables, which are often not clearly set apart (indeed are confused, even) by certain descriptions as well as L2 grammars; the nature of the 'host' unit to which the various RCs are attached (lexical category, or phrasal/clausal constituent: see also §3.1), and indeed the very existence of a distinction between '(NP-)integrated' (RRCs and ARRCs) and 'supplementary' (NRRCs) relative clauses, to use Huddleston \& Pullum's (2002) terms for these constructions.

Section 3 then develops the distinction between restrictive and what I am calling 'arestrictive' (NP-integrated) relative clauses, highlighting the significance of presupposed vs. non-presupposed RRCs and of definite vs. indefinite NPs containing RRCs or ARRCs (a distinction orthogonal to the RRC/ARRC division); while section 4 examines the opposition between (a-)restrictive and non-restrictive relatives in discourse-pragmatic functional terms. Finally, section 5 summarizes and systematizes the results of the investigation.

\section{RELATIVE CLAUSES: STRUCTURAL PROPERTIES}

\subsection{Relative clause introducers vs. relativized variables}

First of all, what is a 'relative clause'? Essentially, an 'integrated' relative is a subordinate clause which is embedded within an NP, and which functions as a modifier (and not as a complement) of the head noun of that NP (see e.g. McCawley 1981, Fabb 1990, Huddleston and Pullum 2002). A restrictive relative acts as a 'syntactic adjective' (Benveniste 1966: 222), a 'restrictor' (Dik 1997: 25) or an 'attribute' (Schachter 1973: 42), in the sense that it further specifies the defining property that any entity capable of being referred to by the NP as a whole must necessarily possess. As a predicate, it serves to restrict the broad intensional categorization already made of the referent at issue by the head noun (itself a predicate, as a common noun) which is modified: cf. also Chierchia \& McConnell-Ginet (1990: 330). An arestrictive relative (see below), however, serves simply to elaborate the denotation of the head noun of the containing NP.

As we have just seen, RRCs are not the only type of NP-integrated relatives: see subsections 3.2, 3.3 and below for a discussion of what we might call 'a-restrictive', but nevertheless 'integrated', relative clauses. ${ }^{2}$ An ARRC, often embedded within an indefinite

\footnotetext{
2 Denison \& Hundt (2013: 142), following Sigley (1997), term these 'aspective' relatives. These are said to be
} 
NP, conveys discourse-new non-identifying information which is nonetheless relevant to the entity being designated by the containing $\mathrm{NP}$ as a whole in terms of its role in the broader discourse context being developed. An attested example is given in (1) (see subsections 3.2 and 3.3 below for more in-depth discussion):

'(...) COMEDY Joe Orton's play is about money hidden in a coffin that gets buried in a churchyard....' (Film synopsis, "Loot", Radio Times 30.07-05.08.16, p. 37)

Since it is clearly necessary to find a term which covers the subset of NP-integrated relatives which in no sense 'restrict' the host head noun's sense, we are proposing the term 'arestrictive' (i.e. 'neither 'restrictive' nor (strictly speaking) 'non-restrictive'), retaining 'restrictive' for integrated relatives which genuinely serve to restrict the sense of their head noun host.

In communicative terms, while RRCs help recipients pick out or identify a particular referent, NRRCs, which are in apposition to their host phrase or clause, do not: their use assumes that the referent of the relative pronoun has already been identified, and they serve simply to add further, non-identifying (though discourse-relevant) information about it. Indeed, as fully-fledged discourse units corresponding semantically to complete predications, carrying a potentially independent illocutionary force in relation to the main clause, NRRCs perform certain specific functions within the wider discourse: see Loock $(2007,2010)$ and $\S 4.2$. Integrated relatives (ARRCs and RRCs), on the other hand, correspond semantically only to (complex) predicates. As such, they do not correspond to potential discourse units, unlike NRRCs (cf. Cornish, 2009: 584).

Now, since the relation involved in the case of RRCs as well as ARRCs is contracted with the head noun of its containing NP (as will be argued below: cf. §3.1), the relation cannot be one of coreference, stricto sensu, where each member of the relation individually targets the same external referent. Hence, quantified, non-referential hosts are just as acceptable as definite, referential ones, though often unacceptable in NRRCs (see $\S 4.1$, and in particular fn. 21, for evidence and illustration). RRCs and ARRCs involve a relation of anaphora $^{3}$ between an NP's head noun and the relative pronoun, while NRRCs normally contract a relation of coreference between the relative pronoun and an independently-referring phrase or clause in its immediate vicinity (see §4.2). Yet many authors (e.g. Malan 1999: 43 and passim) write indiscriminately of a relation of 'coreference' between relativizers and their antecedents in the case of NP-integrated relatives, and between relative pronouns and phrasal heads of various types in that of clause-external or non-restrictive relatives (though Malan's book is in effect restricted solely to integrated relative clauses).

Arguably, the host noun in the case of integrated relatives is not an 'antecedent', in the traditional sense, but rather an 'antecedent trigger' in Cornish \& Salazar Orvig's (2016: 634) conception: ${ }^{4}$ it simply provides the sortal category of entity which is to be built into a fully-

\footnotetext{
3 More exactly, it is a relation of referential dependency, with the host unit having lexical, not phrasal or clausal status, and hence not being a potentially referring expression in its own right. Note that, while a given indexical marker may be simultaneously anaphoric and coreferential with respect to some other expression in a co-text, these functions are nonetheless distinguishable (i.e. in any given instance, there may well be a relation of anaphora without coreference, or of coreference without anaphora). In contrast, as Bhat (2004: 81) briefly mentions, the notions and terms 'anaphora' and 'coreference' tend to be considered as equivalent in the relevant literature.

${ }^{4}$ According to this view, there is a complex interaction in all instances of indexical reference amongst the dimensions of text, context and discourse: thus the text itself is not the sole, unique factor at work in this. This interaction involves an initial occurrence of a relevant antecedent trigger (a verbal fragment, non-verbal signal or percept) at the textual level, which will then give rise to a contextually-determined antecedent which is associated with its referent on the discourse plane. This 'antecedent' is a discourse representation providing a provisional description in terms of what is predicated or inferred of the discourse referent to which it relates. In the case of relative head nouns, the antecedent trigger would simply evoke the sortal category of entity which is to be created discursively; and the actual 'antecedent', in this sense, would be a function of the
} 
fledged referent via the anaphoric (here relative) clause itself. It is only when the interpretation of the whole NP is set up that such a referent may be established, the relativized variable (see below) constituting a proxy for this. And in the case of NRRCs, it seems clear that the RC has a similar function, perhaps clearest of all in the case of propositional NRRCs, where the $\mathrm{RC}$ has the effect of actually creating its referent from within the immediately preceding co-text, as in (2):

'(...) He's [Garrison Keillor] just stopped hosting A Prairie Home Companion, which is a tragedy...' (Interview with Susan Rae, Radio Times 30.07-05.08.16, p. 17)

Here, the NRRC consists of a predicate nominal clause interpretable as ' $\mathrm{X}$ being a tragedy'. As such, for reasons of discourse coherence, it is more likely to target a propositional host, namely 'the fact that GK had just stopped hosting the programme A Prairie Home Competition at the time of utterance' than the programme in question itself (which would constitute a nominal NRRC host): but the programme itself is not a 'play', and its title could not sustain an eventive interpretation. ${ }^{5}$

Syntactically, a relative (of whatever type) is a constituent of the type $\mathrm{C}^{\prime \prime}$ (i.e. it has the structure of a clause) in $\mathrm{X}^{\prime}$ syntax. ${ }^{6}$ In English, it may either be introduced by a relative pronoun in $w$ - or (if an integrated relative) by a relative marker - henceforth 'RM': that or zero - followed by an incomplete clause: what is missing here is the constituent which has been relativized. This missing constituent (more exactly, the unexpressed constituent which is bound by the pronoun and which Dik 1997: 3 terms 'relativized variable' - henceforth 'RV') is perceptible once the introducer is omitted, since the sequence of elements which remains will not then correspond to an independent, stand-alone sentence. Rather, it will contain a gap in a particular functional position in the clause, a gap whose functional-syntactic role is reflected by those clause-introducing wh-pronouns that show case information (i.e. who, whom and whose: cf. also Chierchia \& McConnell-Ginet 1990: 331). In the case of the place and time wh-markers where and when (which are relative adverbs rather than 'pronouns' stricto sensu), the gap is less easy to detect in this context, these forms not being strictly argumental in character. For example, in The city [where John met Mary] is in France, the outcome John met Mary appears at first sight to correspond to a possible sentence; however, it is a 'system sentence', not a 'text sentence', in Lyons's (1977: 622-635) terms, since it would be wanting as a potential utterance. The place (as well as time) at which the meeting indicated occurred would be highly assumed. As a potential text sentence, then, such a construction would be felt as incomplete in context (unless of course the place variable was bound by default in a given context).

Henceforth, a relative marker realised in the English examples by zero will be symbolised as $\varnothing$, and the relativized variable as $\mathbb{B}$. The relative pronoun both signals the subordination of the clause it introduces in relation to the main clause, as well as to the head noun of the containing NP, and binds the relativized variable that corresponds to the referent that is common to the two clauses. The relative marker is fused morphologically with the relative operator in the shape of a relative pronoun (cf. also Dik 1997: 48).

This distinction between 'relative marker' and relativized variable (expressed in the languages exemplified below by an ordinary pronoun: nó in (3a) and masa in (3b) can be illustrated by examples drawn from two unrelated African languages, Akan (3a) and Hausa (3b):

entity constructed via the content of the entire RC itself, in combination with the determiner selected.

5 As is possible with proper names which conventionally denote events, as in (i) Yalta was a tragedy for central and eastern Europe.

${ }^{6}$ See Aarts (2013: 103-128) for a recent accessible introduction. 
(3) (a) àbòfrá [áà me - hú- ù nó]

child RM 1SGSUBJ. see-COMPL ${ }^{7}$ DEF

'a child that I saw' (lit. 'a child that I saw him') (Schachter 1973: 23, ex. (11c), slightly modified. Thanks to Kweku Osam for help both with the example itself and the glosses)

(b) yaron $\quad$ da suka gaya masa $]$

boy-DEF RM 3PL.REL.PERF tell to-3MSG

'the child (boy) that they told' (lit. 'the child that they told him') (Schachter 1973: 23, ex. (12c). Thanks to Philip Jaggar for the glosses)

These data reveal very clearly the distinction between the relativized variable (marked in situ by an ordinary pronoun) and a simple clause-introducing element in relative clauses: áà in (3a) and $d a$ in (3b). According to Jacobson (1989: 201), a number of other languages (e.g. Albanian and Tagalog) introduce relative clauses by means of a marker identical to a subordinator; and McCloskey (1979) argues that this is also the case in modern Irish (cf. also Chinese, according to $\mathrm{Pu} 2007$, where it is null).

However, the existence of the RV is left out of account by descriptions of relatives in standard English such as Quirk et al. (1985) and Malan (1999), who systematically conflate RC introducers (whether wh-pronouns, that or zero) and RVs by characterizing all these introducers, respectively, as directly assuming syntactic-functional roles in the clause, or as being 'in subject or complement position'. Of course, they do and are not, the structural positions within the clause being distinct in each case - even when the RV occupies subject position in it.

\subsection{Relative markers vs. wh-marked relative pronouns. Distribution and functions}

In English too, RMs and relative (wh-)pronouns may be distinguished: that in English is arguably not a relative pronoun, ${ }^{8}$ but simply marks a departure from and (indirectly) a connection with the main clause, and signals that the clause it introduces is subordinate.

Yet Malan (1999: 12) and Larreya \& Rivière (2010: 354) specifically claim that whereas the complement clause introducer that is a pure 'conjunction', the relative clause introducer that (and even zero) is a relative 'pronoun', which, as such, fulfils syntactic functions within the clause. (See also Quirk et al.'s 1985: 366 Table 6.33 as well as van der Auwera 1985 and Loock 2010: 14-15 for such a position). We may surmise that this conception is a direct consequence of these authors' conflating the RV and the relativizer, a position which necessarily entails that that and zero as RC introducers must also be 'relative pronouns'. However, this subsection gives evidence that the distinction between complementclause that and RM that is invalid, and that the that (as well as zero) of relative clauses is also a simple subordinator. In this context, it is a pure relative marker (see also Dik 1997: 48, fn 4, Miller 2008 and Miller \& Fernandez-Vest 2006):

\footnotetext{
7 'COMPL' signifies 'completive aspect'. Akan is an aspectual language, which has no tense system as such, according to Kweku Osam (p.c.). See Osam (2003) and Arkoh \& Matthewson (2013) for further details of Akan.

8 See also Huddleston \& Pullum (2002: 1056-7), Jespersen (1927: 162-168), Schachter (1973: 27, fn. 9), Miller \& Fernandez-Vest (2006: 49-54) and Miller (2008: 72). Van der Auwera (1985), Sag (1997: 462-4) and Chierchia \& McConnell-Ginet (1990: 331), however, argue in favour of the contrary position - the last-mentioned authors also stating, nonetheless, that relative pronoun status is 'questionable' (ibid.p. 331) in the case of that.
} 
(4) $<\mathrm{x} \mathrm{c32}>(\ldots)$ they were cracking jokes about it during one of the shows we went to see

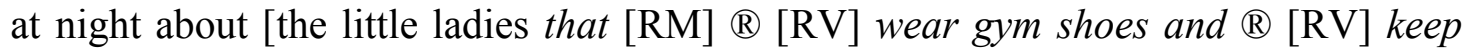
five machines going]... (Spoken extract from 'The great American sandwich' corpus)

Note here that the $\mathrm{RC}$ introducer that, a purely grammatical morpheme in its guise as a subordinator, is thereby neutral as to the 'human' vs. 'non-human' distinction encoded by the veritable relative pronouns who vs. which, respectively. Cf. also Quirk et al. (1985: 1248).

Let us first briefly review some of the main members of the set of English relative pronouns. In standard English, there is the series of relative pronouns in wh-: what (indefinite, non-human), which (definite, specific non-human), who/whom (human), whose (who + the possessive morpheme), ${ }^{9}$ where (place), when (time), etc. However, in current spoken as well as written English, the 'place' relative pronoun/adverb where tends to be used more abstractly, in a more general 'locating' sense (see examples (5a and b) below). Apart from the forms who (subject), whom (non-subject) and whose (genitive), wh-pronouns are not specified for grammatical function: they may bind subject, direct, indirect or oblique object RVs. These features (case-marking where it applies, restriction or otherwise to human referents, to places or times, or to specific or non-specific entities - e.g. which vs. what) are characteristic of pronouns cross-linguistically, being potentially referring expression types, though not of subordinators, which are purely grammatical elements. Note that what, unlike the other whpronouns, contains its own 'antecedent', namely that (+ which): cf. Quirk et al. (1985: 1060). It is this factor, arguably, that accounts for the fact that, alone among the wh-pronouns, there is no 'gap' (RV) in relatives whose introducer is what.

We find $w h$-pronouns in a-restrictive relatives, as in $(5 a)$, restrictive relatives $(5 b)$, non-restrictive (appositive) nominal relatives (6) and propositional relatives (7): see also example (2) above:

(5) (a) Jim Davidson hosts the snooker game show where world-class players compete against the clock to win prizes for the contestants...' (TV programme note, Radio Times 11-17.08.01, p. 66)

(b) '...All through school I knew that I wanted a job where I used my brain but also helped people....' (Interview with Jo Hardy, Radio Times 16-22.08.14, p. 21)

(6) '...A recent study by Oxford University, which compared blood levels of B12 in 689 men, found that 52 per cent of vegans, 7 per cent of vegetarians, but only one omnivore, were vitamin B12 deficient...' (Michael Mosley, Radio Times 16-22.08.14, p. 9)

(7) $<\mathrm{x}$ c28> '(...) so he said if you don't play the machines somebody else is losing an awful lot of money you know which is true' (Spoken extract from 'The great American sandwich' corpus)

Note first of all that neither that nor zero could replace the wh-pronoun/adverb where in the nonetheless integrated relative clauses in $(5 a)$ and $(5 b)$. These RMs would also be ruled out almost by definition as clause introducers of the non-restrictive relatives in (6) and (7) (cf. Quirk et al. 1985: 1257, Dik 1997: 39; see Loock 2007, 2010 and $\S 4.2$ below for this

\footnotetext{
9 As Quirk et al. (1985: 370) point out, the relative (though not interrogative) pronoun/determiner whose, unlike personal who $(m)$, is used in current English not only with personal hosts, but also with non-personal, inanimate ones.
} 
subtype). Corpus data confirm the virtual absence of that as a NRRC introducer too. ${ }^{10}$ The reason for this exclusion may be adduced as follows:

This function evidently normally requires the use of a pronominal, referential expression, something which RMs are not. Since the relative clause is non-restrictive in each case, it is syntactically and semantico-pragmatically quasi-independent in relation to the main clause. This may be expressed formally by the possible presence of a comma before and after the relative clause (and by pauses or other disjunctures in the spoken realization).

Now, in order to co-refer with a phrasal or clausal antecedent across the 'barrier' represented by the comma or the pause/disjuncture, a referentially stronger expression-type than a simple subordinator like that or $\varnothing$ is needed. Wh-marked relative pronouns may occur here, since they are precisely pronouns, a type of expression capable of having a reference. Subordinators, on the other hand, serve only to ensure the connection between main and subordinate clauses, simultaneously signalling the presence of the latter. But there is no tight connection between main clause and NRRC - in fact there is a syntactic break between them: hence an essentially clause-connecting marker such as subordinator that cannot naturally occur, given that the two clauses are by definition not being integrated into a subsuming syntactic unit. ${ }^{11}$ However, this characterization is no doubt too strict a description, in view of the (albeit undoubtedly marginal) attested instances of that introducing NRRCs noted in fn. 10. To avoid any possible confusion, it is important to strictly distinguish between the distal demonstrative determiner/pronoun that (as in Look at that bird, What is that?, respectively) and the subordinator that which we also find as RM - which has a somewhat different phonology: /ðət/ as opposed to /ðæt/ (see also Quirk et al. 1985: 1251, n. (a), Malan 1999: 12).

Note also the close parallelism between that and zero in their RM function, on the one hand, and the very same morphemes as introducers of other types of subordinate clauses, on the other. Just as that and zero may introduce relative clauses modifying a head noun within

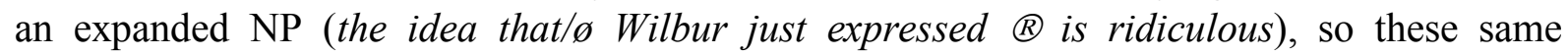
subordinators may herald clauses acting as complement of an (abstract) head noun (and also of certain head verbs, adjectives or prepositions): the idea that/ø Wilbur might not accept the invitation is ridiculous. ${ }^{12}$

Moreover, in contexts where a wh-pronoun introduces a NRRC as an independent utterance, unaccented that is excluded (see $(8 \mathrm{~b})$ in contrast to $(8 \mathrm{a})$ ):

(a)

$$
\begin{aligned}
& \text { '... I may now drive a Ferrari, but at heart, "my other car" will always be that } \\
& \text { Vauxhall Cavalier. Which is as it should be...' ('My other car's a Ferrari', J. } \\
& \text { May, Radio Times, 9-15.08.14, p. 19) }
\end{aligned}
$$

\footnotetext{
10 See Loock's (2007: 359) Appendix A, which tabulates a variety of features of his 450-utterance corpus of written appositive relative clauses (ARCs, in Loock's usage) drawn from journalism (both quality and tabloid), works of fiction and specialised texts. In none of the three subtypes of ARCs he identifies was the subordinator that used as a clause introducer. In the book-length development given in Loock (2010: 14-15), he does give attested examples ((23)-(26), reproduced from Huddleston \& Pullum 2002: 105), where NRRCs are in fact introduced by that; though here, Loock seems to agree with H \& P's position that such instances are marginal - his own corpus containing only a few examples of this, 'sometimes of debatable status'. Loock (2010: 14-15) cites several other corpora which contain extremely small numbers of such examples, or none at all. Quirk et al. (1985: 1257) likewise restrict possible NRRC introducers 'typically' to wh-pronouns. And in Quirk (1957: 102), the author noted among the spontaneous productions of educated speech in an experiment he conducted, that only one instance out of a total of 174 NRRCs was introduced by that. He further comments that when his subjects were subsequently given the choice between that and a wh-pronoun as an NRRC introducer, the wh-pronoun was preferred in every instance.

${ }^{11}$ Emonds (1979: 229) makes essentially the same point, tellingly characterizing the situation thus: '...appositive relatives cannot be introduced by the subordinate finite clause marker that, as can restrictive relatives.' (my emphasis)

12 See already Jespersen (1927: 165-168).
} 
(b) *....That (/ðət/) is as it should be.

Let us look now at the situation where the relative pronoun is governed by a preposition:

(9) '...Twistily plotted while also subtly knowing this [film] has nimble wisecracks with which couples everywhere can readily identify....' (Film synopsis, "Date night", Radio Times 30.07-05.08.16, p. 33)

(10) I'm looking for a piece of paper on which to write my list.

When the preposition (where it is a short and common one: cf. Quirk et al. 1985: 664) is left stranded at the right edge of the clause, the RC introducer may be expressed as that or zero, occurring in situ. This realisation is characteristic, precisely, of the spoken language, but it also occurs even in careful writing:

(9) (a) ... nimble wisecracks $\varnothing$ couples everywhere can readily identify with $\AA$...

(10) (a) I'm looking for a piece of paper $ø$ to write my list on ${ }^{\circledR}$.

As is well known, the RM that cannot 'replace' the relative pronoun when it is preceded by a preposition (see (9b) below), but it may occur when the preposition appears at the end of the clause: see (9c), also below. This is yet another indication that this form is a relative marker and not a fully-fledged 'relative pronoun', as is often stated - since in these positions following a preposition, it is clear that an argument filler is needed.

Now, relative pronouns, which are indeed argument fillers, may occur here, but relative markers (purely grammatical elements, in fact subordinators) are excluded. In addition, in such a position, that assumes its usual function of subordinator, signalling the presence of a subordinate clause (see (9c) below):

(9) (b) *...nimble wisecracks with that couples everywhere can readily identify ...

(9) (c) ...nimble wisecracks that couples everywhere can identify with ${ }^{\circledR} \ldots$

Again, this correlates with the possibility of ellipsis of that in (9a): where that is possible, the zero form is too (on condition that the RV is non-subject). But the converse is not true, as can be seen in (10a) as compared to (9a): whereas in (9a), that and $\varnothing$ are acceptable in the same position as introducers of the relative, in (10a), only the zero form is (cf. *I'm looking for a piece of paper that to write my list on). This is certainly due to the fact that that as a relative marker/subordinator is restricted to occurring in finite clauses (which the subordinate clause in (10a) is not). If it were a 'relative pronoun', however, it should be able to occur in this position. Purely in terms of respective distributions, note that this restriction does not apply to genuine ( $w h$-marked) relative pronouns, at least in the case of the so-called 'free' relatives: He doesn't know [what to do]/[where to go $] /[$ who to turn to $]$, etc.

\section{RESTRICTIVE VS. A-RESTRICTIVE (NP-INTEGRATED) RELATIVE CLAUSES}

Let us distinguish now between ARRCs (introduced in §2.1) and RRCs. We start by briefly examining RRCs. 


\subsection{Restrictive relatives}

First of all, as we will be seeing later, it is important to distinguish between presupposed and non-presupposed RRCs, a distinction orthogonal to that between definite and indefinite RCcontaining NPs. The two examples presented in this subsection illustrate the first subtype within the former distinction, and example (5b) the second - all three of these RC-containing NPs being indefinite. So although a restrictive relative may well serve to set up a narrower category type than the one denoted solely by the head noun which it modifies, nevertheless, its content is not necessarily presupposed by the speaker or writer. The 'presupposed/nonpresupposed' opposition is limited to RRCs, ARRCs being by definition non-presupposed, and NRRCs by definition corresponding only to assertions (or other mood and illocutionary categories) at the utterance level. To begin, here is an example of a restrictive relative, where the illocutionary force of the containing NP in context was that of a question (pronounced with a rising tone):

$<\mathrm{x}$ k4> any other fascinating drinks [that you tried $\left({ }^{\circledR}\right]$ (Spoken extract from 'The great American sandwich' corpus)

As a modifier, the relative clause may, in principle, be elided without any consequence for the remainder of the sentence - on condition, from the discourse point of view, that the referent of the resulting NP (any other fascinating drinks in (11), an NP which arguably does not exist as such prior to the elision of the RRC - see below), is already grounded in the preceding context.

By contrast, Fox \& Thompson (1990: 298, fn. 4) claim a contrario that what is modified by a relative clause is in fact an 'NP' (cf. also Bache \& Jakobsen 1980, Quirk et al. 1985), and not the head noun of the embedding NP containing the relative. On the basis of the data yielded by their corpus of American English conversational utterances, these authors do not, however, distinguish between RRCs and NRRCs (this is also the case with Biber et al. 1999: 603).

In the approach adopted here, however, the sequence Determiner + Noun preceding the RRC is not in fact a constituent as such: an 'NP' should be substitutable by a pronoun, yet this is impossible in the context of a restrictive relative: The book/*It that I read yesterday. Furthermore, the article or other determiner which introduces the NP as a whole functions to establish in context the reference of the entire content of this NP (i.e. head $\mathrm{N}+$ relative clause), and is in a paradigmatic relation with every other member of the determiner set. The analysis we are claiming to be valid here, then, posits the structure of English integrated

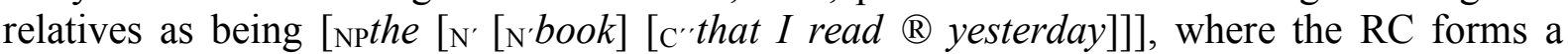
head-modifier constituent with the head noun of the expanded, containing NP, and not [NP[NPthe book] [C'that I read ${ }^{\circledR}$ yesterday]] (Cf. also Loock 2010: 10 and $\S 4.1$ below). ${ }^{13}$ Under this analysis, the definite article the determines the entire head noun + RRC complex, and not simply the $\mathrm{N}$ book. The same is certainly true of other NPs containing modifiers (eg. APs or PPs: respectively, the [book [bound in gold braid]]/...[about philosophy]]). See also as evidence the ungrammaticality created by attempting to substitute an indefinite pronoun for

\footnotetext{
13 But this is contrary to what is indicated in Quirk et al. (1985: 365) as the structure of a very similar example (see below). Nevertheless, the authors indicate just above this representation that the relative pronoun which in their example ([the book [which you ordered last month]]) has as its 'antecedent' only the head noun book; yet in their subsequent analyses of English relative clauses, the authors explicitly state that the 'antecedent' of RRCs is an NP, and not the head noun alone (e.g. Quirk et al. 1985: 1048). Aarts (2013: 238) also does not distinguish syntactically between RRCs and NRRCs, claiming that the difference lies solely in their semantic interpretations. He represents both subtypes as adjuncts attached to an $\mathrm{N}^{\prime}$.
} 
the 'NP' preceding the relative clause in $(12):{ }^{14}$

'...two films about art [that ${ }^{\circledR}$ is produced by those with no formal training].' (Film synopsis, Outsider Art, Radio Times 11-17.08.01, p. 85)

Replacing the 'introducing NP' (but see note 14 for an alternative 'substitutum') two films about art here by ones would not result in a grammatical matrix NP: *Ones that is produced by those with no formal training. For in (12), the singular value of the finite passive auxiliary verb is in the relative clause relates to the 'host' of this integrated relative, namely the head noun art (SG.), and not to the 'NP' (at least, in the context of this restrictive relative clause) two films about art (PL.). This formal-syntactic relation reflects the fact that the relative clause in (12) functions to set up a restriction upon the denotation of the head noun art, thereby creating a subcategory of 'art'. Namely, art produced by artists without any formal training in the field.

\section{2. 'A-restrictive' relatives}

Let us look now specifically at 'a-restrictive' relative clauses (ARRCs). Below are several attested illustrations:

(13) 'Philip LeRiche is a retired software developer and information security adviser and Ben Skidmore is an electronic engineering student. Both volunteer with The Restart Project, a London-based social enterprise that encourages and empowers people to keep their electronic goods for longer (...)' (The Guardian On-Line, 16.06.14).

Here, the NP-integrated relative clause that encourages and empowers people to keep their electronic goods for longer conveys discourse- and hearer-new information for the reader at the point of occurrence. It does not restrict the reference of the NP that contains it, thereby helping the reader to identify the referent at issue. No contrast is implied with other 'Londonbased social enterprises', which would be the case if the relative clause were restrictive (see $\S \S 3.1$ above and 4.1 below). Indeed, the indefinite NP that contains it is in apposition to the proper noun which precedes (The Restart Project), and as such serves to inform the reader about this venture. Notice that no radical change in terms of the referent targeted by the residue of the omission (in effect, forming a simpler indefinite NP) would be caused if the ARRC were elided. This state of affairs is in direct contrast with the situation obtaining with restrictive relatives. Note however, as we have already seen in subsection 3.1, that RRCs may well also occur within indefinite NPs. As such, they often serve to characterise a type of entity.

(14) and (15) are further attested indefinite-NP-containing examples of ARRCs:

(14) 'It's inspired by the most successful rally car of the 90s, so expect a sports saloon that exhilarates...' (Advertisement for Subaru cars, Radio Times 7-13.08.99, p. 11)

\footnotetext{
14 Note that the pronoun one $(s)$ does not in fact require a parallel syntactic constituent as textual antecedent, and does not even have to anaphorise a semantically coherent representation (cf. Keizer 2012: 408-9, according to the corpus data which this author adduces). Hence it is quite possible that, as a type-denoting indefinite pronoun, ones in the modified version of this example below is interpretable simply as 'films about art', an $\mathrm{N}^{\prime}$ in terms of syntax, rather than as a function of a fullblown NP (see also Cornish \& Salazar Orvig 2016: 68).
} 
(15) '...[(actor) Steve] Martin displays a comic dexterity which since then he seems to have lost or perhaps put aside...' (Barry Norman, "Last of the clowns...", Radio Times 713.08.99, p. 42)

In (14) and (15), the governing verbs expect and displays imply that the states of affairs evoked by the complex NPs which they govern are either one which is predicted to materialise in the future (from the intended buyer's point of view in (14)), or one that is claimed to hold, as in (15). These indefinite NPs therefore constitute discourse-new, focal information. (16a), however, is an ARRC contained within a syntactically definite NP:

(16) a '(...) DOCUMENTARY Chris Rock's amusing yet piquant look at the billiondollar industry that thrives on the care and treatment of black hair weaves a worthy tale...' (Film synopsis, "Good hair”, Radio Times 30.07-05.08.16, p. 38)

b '(...) Bobby Charlton tells the story of the Munich air disaster. He charts a journey that ended in the tragic events of 1958.' (Film synopsis, "Yesterday" TV channel, Radio Times 30.07-05.08.16, p. 49)

In (16a), the nature of the industry examined in the documentary at issue is in fact discoursenew (and also reader-new) information: as such, the NP which expresses it would be indefinite in the absence of the relative (in fact, the definite article introducing the original NP could be replaced by the indefinite one). So this is an example where, by hypothesis, it is the addition of the relative clause itself which has caused the NP as a whole to be syntactically definite. After all, eliding the RC here implies that the referent of the residue is discourse-new (indeed, there would be no justification for a definite (i.e. functionally anaphoric) RC-less NP at this point in the brief synopsis, namely, the very first sentence). The referent in each case is thus essentially identical. The 'lie (contradiction) test' (see the next subsection) confirms this status, since it yields a positive result when the content of the RC is contradicted: That's not true at all, it doesn't!. We may say that the $\mathrm{RC}$ in (16a) is at the same time speakerpresupposed (since the journalist has manifestly already seen the documentary in question) as well as discourse- and reader-new.

As for (16b), this represents the opposite configuration to (16a): for here, the RCcontained NP is indefinite, rather than definite (as would befit the highly presupposed character of the RRC involved here: indeed, the definite article in place of the indefinite one would be highly preferred). The 'heralding' NP the Munich air disaster and the evocation of the famous former Manchester United and England footballer 'Bobby Charlton' in the initial sentence, as well as the also definite NP the tragic events of 1958 within the RC itself, serve to trigger the memory of this well-known air catastrophe. The RC thus represents highly presupposed specific knowledge on the reader's part - and yet the containing NP is indefinite.

Malan (1999: 5-6) also notices the distinction between what we are calling restrictive and a-restrictive integrated relatives. However, her solution (1999: 6) is to abandon the term 'restrictive', since clearly it is only a 'subset' of this category which really serves to 'restrict' the reference of the NP which contains the relative clause. She proposes instead the cover term 'relative déterminative'. Yet this does not capture the specificity of what we are calling 'ARRCs' (she calls these 'fausses déterminatives', which is not a very helpful term, ARRCs not being 'déterminatives' — i.e. 'restrictive' — at all).

Depraetere (1996: 718-720), for her part, tacitly recognises the distinction between ARRCs and RRCs, though she continues to use the cover term ' $R R C s$ ' to categorize both subtypes. According to the author, ARRCs (in our terms) occurring within indefinite NPs serve to signal discursively foregrounded information, whereas relatives embedded within 
definite ones only convey backgrounded content. ${ }^{15}$ However, our example (16a) is clearly a counterexample to this latter claim. Rydén (1974: 544-5) similarly distinguishes a 'descriptive or characterizational' (p. 544) RC type, though he is equivocal about its distinctiveness with regard to NRRCs, and does not give it a particularizing label.

\subsection{Distinguishing between a-restrictive and restrictive relatives}

Three tests, amongst a number of others noted in the relevant literature, make it possible to recognise (a-)restrictive relative clauses. The first of these corresponds to an interpretation, or initial analysis, of the clause in terms of the type of semantic contribution being made by the $\mathrm{RC}$; and the next two seek either to confirm this initial understanding (test 2) or to provide evidence that it is presupposed (confirming its RRC status) or not (indicating that it may either be a non-presupposed RRC or an ARRC: test 3).

Test 1: The nature of the semantic contribution made by the subordinate clause as a whole. If it is a restrictive relative, then it serves to determine more precisely which ' $\mathrm{x}$ ' is involved in the reference of the NP as a whole. A-restrictive relatives lack this property (see $(17 b))$ :

(17) (a) The book [that was ordered yesterday] is out of print. (= identificational, reference-restricting)

(b) You bought a book [that is being considered for the Pulitzer prize] yesterday. (= nonidentificational, non reference-restricting; merely elaborating in function: implied evaluation by the speaker of the book in question)

Test 2: If we elide the relative clause as a whole, on condition that the unmodified head noun of the residual NP is not a general or highly abstract one, then if it is a restrictive relative (as in (18a), modified from (17a)), the resulting NP's referent will be a different one. However, if it is an a-restrictive relative, then the referent will be essentially the same, whether the relative is present or not, as in (18b):

(a) \#16 The book is out of print. (referent of NP the book is contextually unanchored; probably distinct from that of the subject NP in (17a))

(b) You bought a book yesterday. (referent of NP a book is newly introduced; it could well correspond to the book evoked in an utterance of (17b))

This test often yields more perspicuous results when the containing NP is indefinite: viz., $I$ wanted a job vs. I wanted a job where I used my brain but also helped people, as in (5b) above. Here, the referents of the object NPs are clearly distinct (that of the latter being a more specific subtype of the former). Test 2 indicates whether a $\mathrm{RC}$ is restrictive or otherwise, not whether its content is presupposed by the speaker or not. This is the purpose of Test 3 . In the case of (5b) and (19) (below), for example, the sub clauses are not presupposed, even though they are clearly RRCs:

\footnotetext{
15 In contrast, neither Quirk et al. (1985) nor Sag (1997) appear to countenance ARRCs within their respective accounts of English relative clauses at all - even though each provides a broad coverage of the area. And Bache \& Jakobsen (1980) near systematically confuse ARRCs (which they do not recognize as a distinct subtype) with RRCs in attempting to demonstrate the supposed close parallelism between 'RRCs' and NRRCs.

16 The crosshatch symbol used here and subsequently serves to indicate that the utterance so prefixed is infelicitous in context, even though it may also be perfectly grammatical as well as semantically well-formed at the same time.
} 
(19) '...Here's my pick of the players who'll make this one of the most exciting seasons yet.' (Alan Hansen, 'The players to watch...'. Radio Times 7-13.08.99, p. 26)

Test 3, the so-called 'lie-test' (see Erteschik-Shir 2007: 39, 164): This is really a test of what is in focus in a given utterance. If the content of a given segment can be felicitously contradicted, then it is indeed in focus, discourse-pragmatically; but if it cannot, then it is part of the presupposition of the utterance concerned. ${ }^{17}$ The test should be construed in relative, not absolute terms: the relative degree of ease with which the contradiction may be realised reflects the degree of 'foregroundedness' of the information unit at issue. Let us apply this test to both the matrix and the relative clauses presented earlier in this subsection (see (20) for RRCs, and (21) for ARRCs). The relevant contrast is that between (20a.B) and (21a.B):

(20) (a) A, to B: The book [that was ordered yesterday] is out of print.

B: \#That's not true at all, it wasn't! (Contradiction of the content of the RC)

(b) A, to B: The book [that was ordered yesterday] is out of print.

$\mathrm{B}$ : That's not true at all, it isn't! (Contradiction of the matrix proposition)

(21) (a) A, to B: You bought a book [that is being considered for the Pulitzer prize] yesterday.

B: That's not true at all, it isn't! (Contradiction of the content of the RC)

(b) A, to B: You bought a book [that is being considered for the Pulitzer prize] yesterday.

B: That's not true at all, I didn't! (Contradiction of the matrix proposition)

Now let us apply these three tests to the attested examples that follow:

'...[Will it be] perhaps a genuine novelty such as Sally, Irene and Mary (Saturday), a 1938 Alice Faye musical [that apparently has never before been shown on British TV]?...' ('Quentin Cooper's guide through the multichannel maze', Radio Times 713.08 .99 , p. 39)

(23) '...When you sell a home in America you have to pretend you have never lived there. The inspector's report on the house [ø we sold in Washington] mentioned all manner of minor imperfections...' ('Viewpoint', Justin Webb, Radio Times 02-08.08.14, p. 9)

Applying Test 1 to (22), it is clear that the content of the italicised subordinate clause serves to convey the writer's noting of a feature associated with the musical in question (notice the presence of the style disjunct apparently), namely the fact that this showing would constitute a première on British TV. There is no concern to distinguish it from other comparable musicals in order to identify it. As for Test 2, eliding the RC would not essentially change the referent at issue. Test 3 also yields a positive result: That's not true at

\footnotetext{
${ }^{17}$ However, we cannot simply conclude from the fact that an integrated relative clause constitutes focal information that it is an ARRC, since, as we have seen, there are also RRCs which are non-presupposed - hence their content is to some extent discourse-new information, like that of ARRCs. The profile of non-presupposed RRCs corresponds to the following outcomes of the three heuristics: semantic restriction of the containing NP's head noun (Test 1), a distinct referent evoked following elision of the RC (Test 2), and felicitous contradiction of the RC (Test 3).
} 
all, it has!, clearly indicating that the content of the $\mathrm{RC}$ is part of the focus, but not the presupposition of the containing NP. So it seems we are dealing with an ARRC here.

As for example (23), Test 1 shows that the subordinate clause places a limit or restriction upon the denotation of the noun house: it is a question of the particular 'house' which was situated in Washington and which the writer sold prior to the time of utterance. This is clearly characteristic of a RRC. Test 2 confirms this status: for if the relative clause is elided (The inspector's report on the house mentioned all manner of minor imperfections), then it is not clear at all which 'house' is being evoked: indeed, there is no way that it would specifically be the writer's house that is at issue. So the clause would seem to be restrictive, and not a-restrictive in this respect. Test 3 indicates that the content of the clause at issue is part of the presupposition of the matrix subject NP, and does not constitute focused information (\#That's not true at all, you didn't! versus That's not true at all, it didn't!).

In discourse terms, the content of the ARRC in (22) represents discourse- and readernew information (see also Depraetere 1996: 718); but in (23), the existence of a particular 'house' formerly owned by Justin Webb in Washington is presented as constituting backgrounded discourse information ${ }^{18}$ in the case of the RRC.

Table 1 summarises the criteria distinguishing RRCs and ARRCs in English.

\begin{tabular}{|l|c|c|}
\hline \multicolumn{1}{|c|}{ Diagnostic test } & A-restrictive relative clause & Restrictive relative clause \\
\hline $\begin{array}{l}\text { 1. Semantically, the subordinate } \\
\text { clause serves to restrict the } \\
\text { denotation of the head noun of the } \\
\text { RC-containing NP. }\end{array}$ & - & + \\
\hline $\begin{array}{l}\text { 2. If the relative clause is elided, } \\
\text { the referent targeted by the residue } \\
\text { remains essentially the same. }\end{array}$ & + & - \\
\hline $\begin{array}{l}\text { 3. The content of the relative clause } \\
\text { can be felicitously contradicted (cf. } \\
\text { the 'lie-test'): if so, then it is part of } \\
\text { the focus of the utterance at issue. }\end{array}$ & + & + \\
\hline
\end{tabular}

Table 1

Tests for 'a-restrictive' vs. restrictive relative clauses

\section{DISCOURSE FUNCTIONALITY: RESPECTIVE CONTRIBUTIONS OF INTEGRATED VS. NON-INTEGRATED RELATIVES TO DISCOURSE CREATION}

\subsection{Integrated vs. non-integrated relative clauses}

Integrated RCs (specifically RRCs) may serve to create a type of entity, often as part of an indefinite containing NP. Closely connected with this function is their role in the formulation of definitions (whether in dictionaries or encyclopaedias). They may also help to set up a bound-variable construction, and can function as an extended predicate within an NP (either demonstrative or definite) that acts to direct the recipient towards reactivating an assumed shared item of knowledge buried in the speech participants' long-term memory. NRRCs, however, are not capable of or suited for achieving any of these discourse goals. Let us look at each of these functions in turn.

\footnotetext{
18 Here requiring the reader to accommodate the presupposition involved.

19 The alternative specification '+' here is intended to take non-presupposed RRCs into account (see note 17), where at least the 'lie-test' results in acceptable outcomes.
} 
Since NP-integrated relatives bear upon a particular (common) noun (a form type which corresponds semantically to an intension and only denotes, but does not refer), and not upon an NP, a type of expression which may well be used to refer (to an entity, a set of entities or to a genus - i.e. a generic reference), the nature of the reference of the containing NP is irrelevant:

'...All through school I knew that I wanted a job where I used my brain but also helped people....' (Interview with Jo Hardy, Radio Times 16-22.08.14, p. 21: example (5b) above)

In (24a), the reference of the global indefinite NP whose head is job is non-specific: there is no particular 'job' identified via the use of the expression a job where I used my brain but also helped people. The entity evoked constitutes a type, not a token (note the semantic effect of the governing modalizing, 'world-creating' verb want here). The restrictive relative clause serves precisely to specify the type at issue here. As we have seen, this syntactic dependency upon a head noun in the case of restrictive relatives has a semantic correlate, in that the content of the relative clause serves to extend the sense and, in doing so, to narrow down the denotation of the head noun upon which it is constructed. This discourse function could not be realised via an equivalent NRRC:

(b) $\quad !^{20}$...All through school I knew that I wanted a job, where I used my brain but also helped people....

In (24b), since the now 'orphaned' indefinite NP is non-referential, the purported NRRC has no 'anchor' to support it. The quantifier corresponding to the indefinite article needs to have scope over a constituent corresponding to a coherent semantic unit - i.e. more than simply the denotation of the head noun by itself, as would be the case for the 'NP' consisting of indefinite article + noun in the semantically infelicitous appositional clause in (24b). On the other hand, in the original example (24a) such a constituent is available in the shape of the head noun together with its modifying relative providing the relevant property for its denotatum. In more general terms, quantified or otherwise non-specific, non-referring expressions are not acceptable as hosts for potential NRRCs (cf. Del Gobbo 2003, Loock 2010: 20, Emonds 1979: 235-6), unless they can be interpreted as generic in function. ${ }^{21}$

(25) is an illustration of the function of (non-presupposed) RRCs in formulating dictionary definitions of nouns:

(25) Drayman. 1581. A man who drives a (brewer's) dray. (The Shorter Oxford Dictionary on Historical Principles (3 ${ }^{\text {rd }}$ edition). Oxford: Clarendon Press, 1973, p. 606)

Here, the RRC is an essential part of the definiens of the defined noun drayman. NRRCs, by contrast, tend to be used in dictionary definitions for adding non-essential details about the meaning, or about the type of world entity which the noun in question denotes.

\footnotetext{
${ }^{20}$ The exclamation mark prefixed to this example indicates the semantic infelicity of this example.

${ }^{21}$ Bache \& Jakobsen (1980: 265-266) give what they claim are counterexamples to this (unqualified) constraint with their examples (39)-(41). Here, quantified NPs (respectively, No non-white persons, any lettuce and every modern comfort) occur followed by NRRCs. However, it would appear that these are in fact 'encapsulated' NPs in that all of them evoke generic entities in context ('non-white persons', 'lettuce' and 'every modern comfort', respectively). Thus they refer independently, making them suitable for hosting an NRRC. It is these entities which are anaphorised by the wh-pronouns who or which in each instance. So they are not in fact counterexamples at all.
} 
Now, inasmuch as they are modifiers, relative clauses are in principle omissible. However, as we have already seen in subsection 3.3, an NP containing a RRC and the same $\mathrm{NP}$ without one are not equivalent, whether in semantic or in pragmatic terms. For a RRC post-modifying a noun serves above all to identify the referent targeted, by providing a property enabling the addressee or the reader to differentiate it with respect to other referents with which it might be confused:

(a) $\quad<\mathrm{x} \mathrm{c} 23>$ ' (...) and in the middle of the night the longest train $\varnothing i$ have ever heard in my life went past the bedroom (...)' (Spoken extract from 'The great American sandwich' corpus)

(b) and in the middle of the night the longest train went past the bedroom.

Again, as in (24a), in (26a) the intensional element corresponding to the superlative component of the adjective longest requires a coherent semantic constituent over which it can have scope, forming an expanded property (viz. 'longest $\mathrm{X}$ the speaker had ever heard in her life'). This property is predicated of a restricted subset of long trains, namely 'the particular one which the speaker heard at the time being narrated'; whereas, by default, we understand (26b) as asserting that the longest train in the world, objectively speaking, went past speaker $<\mathrm{x} \mathrm{c} 23>$ 's bedroom at the time being reported. This is potentially a very different entity. As in the case of (24b) as compared with (24a), an equivalent NRRC could not perform the semantic function fulfilled by the RRC in (26a).

As in (26a), when the NP in question contains a logical element, then an RRC is virtually obligatory for the sentence to make sense:

(a) $\quad<\mathrm{x} \mathrm{c19}>$ ' (...) it was the ONE place where $i$ had to stay in a hotel' (Spoken extract from 'The great American sandwich' corpus)

(b) !It was the ONE place, where $i$ had to stay in a hotel.

Here the restrictive phrase one ( + pitch accent) $X$ (followed by relative clause), where the numeral one, which when preceded by the definite article, is equivalent to the restrictive adverb only - i.e. 'the one and only...' -, imposes a logical scope over the whole of the noun group place where $i$ had to stay in a hotel. And it is this that makes the presence of the RRC obligatory in (27a). Note that the restriction here stems both from the presence of the definite article and the fact that one is accented (compare with ... one place where $i$ had to stay in a hotel).

By contrast, in the absence of this integrated relative (see (27b)), the accented numeral one can only have scope over the sole noun head place, a situation which would result in an absurd proposition since this noun has an extremely broad, nonspecific denotatum (cf. also Bache \& Jakobsen 1980: 260).

Administrative prescriptions defining a category of individuals concerned by some specification or condition also require integrated RCs (in (28a) below, a RRC) in order to achieve this function of delimiting a class of entities denoted by the nouns upon which they operate (see $\S 2.1$ above).

(28) (a) Those students who have obtained 26 points at Part I may register for their chosen degree. (Translation from French of a notice displayed in the Language Sciences department, Université de Toulouse II) 
Here, the restrictive relative (in italics) delimits a potential subset of students: namely, those who have obtained 26 points in Part I. It is not a question of all students, whatever their situation, being said to be authorised to register for their first degree, but only those who have obtained 26 points in Part I of their undergraduate programme. Compare this with (28b), where the RC has NRRC status:

(b) Those students, who have obtained 26 points at Part I, may register for their chosen degree.

Though this is also a possible utterance, it does not mean the same as example (28a) at all. For in (28b), all the students in question (i.e. 'those particular students', a group presupposed to have been identified either independently or deictically, via the situation of utterance) are asserted as being permitted to register for their chosen degree, and not only those who have obtained 26 points in Part I (though assertion is not the only type of illocutionary force a NRRC may assume). There may well be other students at the University in question who have obtained 26 points in Part I, but who are not included in the group of students designated by the subject of the main clause. Note also that in (28b), the demonstrative determiner those assumes its usual deictic-referential function. Whereas in (28a), this is clearly not the case. Here the demonstrative may be replaced by a quantifier such as all or any, a substitution which would be impossible salva veritate in the case of (28b). This difference in referential value is a direct function of the differing $\mathrm{RC}$ subtypes at issue in this pair of examples.

Finally, (29) is an example of the use of RRCs to enable the addressee/reader to locate and extract an item of shared, stored information from their long-term memory:

'...Pyle had a flat in a new villa near the rue Duranton, off one of those main streets which the French continually subdivided in honour of their generals...' (G. Greene, The Quiet American, London: Vintage Books, 2004, p. 18)

As we have seen in subsections 3.1 and 3.3, the proposition expressed via a RRC may or may not be presupposed by the speaker as true of the referent of the whole NP containing it, ${ }^{22}$ however, it usually conveys only (relatively) background information, unlike ARRCs or one subtype of NRRCs ('Continuative' NRRCs: see subsection 4.2): see Figure 1 in 4.2 below for an overall representation of the positions adopted by the various subtypes of RC described here on the background-foreground axis, at the level of discourse.

RRCs are crucial for the containing NP's reference, unlike non-restrictive (or 'supplementary', in Huddleston \& Pullum's 2002 terminology) relatives, to which we now turn.

\subsection{Non-Restrictive (Appositive) Relatives}

By contrast, non-restrictive relative clauses, which are precisely, by that token, appositive in function, to some extent function like parentheticals. That is, they break up the flow of the discourse on some referent in order to elaborate or comment on it in some way. See in particular Loock's $(2007,2010)$ subtype of appositive relatives which he calls 'Subjective', where the NRRC evokes an aside, a comment or an evaluation of the host referent or the state of affairs evoked via the main clause. An example:

\footnotetext{
${ }^{22}$ See examples (5b) and (19) above for illustrations of non-presupposed RRCs.
} 
(30) 'A routine Randolph Scott western, uninspiringly directed by Gun Crazy's Joseph H Lewis who fails to secure a satisfactory conclusion to the tale, which results in a particularly soppy ending...' (Film synopsis, A Lawless Street, Radio Times 713.08.99, p. 49)

Here, the (propositional) NRRC which results in a particularly soppy ending constitutes a subjective evaluation on the journalist's part of the lack of a satisfactory conclusion to the story in the film at issue. Note in particular the subjective adjective soppy used to express the critic's point of view on the film at issue here. A test for Subjective status could be the possibility of inserting, without altering the intended interpretation, one of the discourse markers in my view or to my mind after the relative pronoun in (30).

The other two subtypes of NRRC recognized by Loock are 'Continuative' and 'Relevance'. Loock's subtype 'Continuative' involves the NRRC in post-matrix clause position evoking a state, process or event which comes into being after the one evoked by the preceding main clause. As in the case of the Subjective status of the NRRC in (30), a test for Continuative status could be the possibility of felicitously inserting the time adverb later between the passive auxiliary was and forced in (31), for example:

'(...) I used to help out with a local community group, which I was forced to give up due to all the admin'. (The Guardian On-Line, 21.01.14)

This is a 'Continuative' NRRC whose host is a 2nd-order referent (the eventuality 'the writer's helping out with a local community group at the time designated'). Denison \& Hundt (2013: 144-5, ff.) use the same term, though do not (apparently) restrict the subtype to matrix-final clauses which advance the narrative being developed - and hence constitute not only new but also discursively foregrounded information.

Another such example is (32), where it seems that a 'Relevance' relation (see below) is involved simultaneously:

(32) 'Donna Mills plays the battered wife of nasty Corbin Bernson, who summons up the courage to leave him only to discover that he has no intention of allowing her to break up the family...' (Film synopsis of Dangerous Intentions, Radio Times 7-13.08.99, p. 48)

Note here that it is not the referent 'Donna Mills', the actress, that is anaphorised by the relative pronoun who in this NRRC, but the character she plays in the film ('the battered wife of nasty Corbin Bernson'). The NRRC evokes a continuation of the plot description initiated by the first clause, and also enables the reader to infer that this event is a consequence of the character in question's having been 'battered' by her husband: hence there is also a relation of 'Relevance' (specifically, 'Cause-Consequence' here) holding between the two propositions: see below on this subtype. To test for these statuses, the markers as a result (for 'Relevance') and subsequently (for 'Continuative') could be naturally inserted (in that order) after the relative pronoun who in (32). Notice that, where this occurs, one of the discourse-pragmatic statuses is dominant, the most dominant one of all characterising the status of the NRRC as a whole (see Figure 2 below). In (32), this is clearly the status 'Continuative', 'Relevance' being subservient to it. The subtypes of NRRC recognized by Loock are thus not mutually exclusive.

The NRRC subtype named 'Relevance', as the term implies, enables the recipient to grasp the relevance of the situation evoked via the main clause, as illustrated by (33): 
'...The first recorded eclipse prediction may have been made by Greek philosopher Thales, who is alleged to have forecast totality for an eclipse in 585 BC...' ('Eclipses throughout history', Radio Times 07-13.08.99, p. 25)

Here, the content of the NRRC provides the (tentative) evidence for the (again, tentative) claim made by the journalist in the initial, independent clause. To test this, the marker indeed could be felicitously introduced after the passive auxiliary is within the RC. Note also that the states of affairs evoked via the matrix and relative clauses are identical, so the NRRC here cannot (also) be of the 'Continuative' subtype.

See Loock (2010: 95-139) for a detailed discussion of the various discourse functions of the subtypes of NRRCs he recognizes. Of the examples of NRRCs presented earlier, the ones in (6), (in part) (32) and (33) would be of the 'Relevance' subtype, those in (2), (7), (8a) and (30) would be 'Subjective' ones, and (31) and (32) 'Continuative'. As for the remaining example (28b), none of the three subtypes recognised in Loock's typology seems to be relevant, the NRRC simply evoking an additional, elaborative piece of extra information about the referent of the host expression.

In no sense do NRRCs serve to restrict the denotation of their host expression, as we have seen ( $\$ 4.1$ in particular). Unlike NP-integrated relatives, with NRRCs, the clause does not form a constituent with its host, which, contrary to integrated relatives, is a phrasal (NP, PP, AP) or clausal, not a lexical category (N). In such instances, the reference of this phrasal or clausal category is assumed already to be established independently of the content of the relative itself, as we have seen.

As regards the often-mentioned 'suppressibility' property of NRRCs, ${ }^{23}$ Loock's (2007, 2010) corpus-based surveys suggest a significant qualification. For of his three subtypes, Loock claims these surveys show that only the first ('Subjectives') may be omitted in context without consequences for the remainder of the surrounding discourse, the third ('Relevance' NRRCs) being omissible only under certain conditions. However, in general, it appears that the presence or absence of the NRRC does not differentially affect the identification of the host referent to which it relates.

In sum, then, we may say that Continuative NRRCs serve to update the discourse context already created (in part, at least) by the preceding independent clause, while Subjective NRRCs simply act 'metadiscursively' to manage and 'punctuate' the discourse created via the preceding or surrounding co-text. In this they are akin to parentheticals (see Dehé 2014 in relation to spoken English discourse). Relevance NRRCs, for their part, serve to facilitate, by contextualising it, the interpretation by the addressee or reader of the matrix clause within which, or following which, they occur.

Moreover, according to the Appendix given in Loock (2007: 361), virtually all of the three subtypes of NRRCs recognised in the corpus conveyed discourse-new information (respectively, $100 \%, 98.9 \%$ and $100 \%$ ). However, with the exception of Continuatives, this information, though discourse-new, is (relatively) backgrounded in relation to the content of the main clause: see Figure 1 below.

Table 2 summarises the differential properties of the three basic subtypes of relative clause:

\footnotetext{
23 But see Hannay \& Keizer (2005) for evidence that nominal appositions, at least, do indeed contribute to the discourse being created via the host plus apposition nexus. See also Loock $(2007,2010)$ regarding appositive relatives. My point is that, given that appositive relatives are syntactically independent of the matrix clause and function as quasi-independent discourse units, the host phrase should in principle be referentially autonomous with respect to the apposition.
} 


\begin{tabular}{|l|c|c|c|}
\hline \multicolumn{1}{|c|}{ Diagnostic test } & $\begin{array}{c}\text { Restrictive } \\
\text { relative }\end{array}$ & $\begin{array}{c}\text { A-restrictive } \\
\text { relative }\end{array}$ & $\begin{array}{c}\text { Non- } \\
\text { restrictive } \\
\text { relative }\end{array}$ \\
\hline $\begin{array}{l}\text { Eliding the relative clause affects the nature of the } \\
\text { referent targeted. }\end{array}$ & + & - & - \\
\hline $\begin{array}{l}\text { The relative clause expands the head N (a lexeme) of the } \\
\text { containing NP. }\end{array}$ & + & + & - \\
\hline $\begin{array}{l}\text { The relative elaborates a constituent of phrasal or } \\
\text { clausal rank: an appositional relation. }\end{array}$ & - & - & + \\
\hline $\begin{array}{l}\text { If the relative is introduced by a } \text { wh-marked relative } \\
\text { pronoun and, in the case of zero, it relativizes a non- } \\
\text { subject constituent, it can (in principle) be replaced by } \\
\text { that } \text { or by ø. }\end{array}$ & & + & - \\
\hline $\begin{array}{l}\text { There are, or one could insert, commas (in writing) or } \\
\text { pauses and/or tone boundaries (in speech) around the } \\
\text { relative clause. }{ }^{24}\end{array}$ & - & - & + \\
\hline $\begin{array}{l}\text { The relative clause conveys discursively (relatively) } \\
\text { foreground information. }\end{array}$ & - & + & + \\
\hline
\end{tabular}

Table 2

Criteria for restrictive, a-restrictive and non-restrictive relative clauses

Table 2 shows clearly the bi-directional relationship between the central category of ARRCs and the other two categories flanking it to its left (RRCs) and right (NRRCs). There are four properties which they hold in common with the former of the flanking subtypes, and only two with the latter. This indicates that ARRCs tend to pattern as an NP-integrated rather than clause-external type of unit - which contradicts what both Malan (1999) and Denison \& Hundt (2013) claim.

Figure 1 ranges the six subtypes of RC examined in this article along an axis stretching from 'Background' to 'Foreground', through 'Midground', at the level of discourse:

\section{BACKGROUND MIDGROUND FOREGROUND}

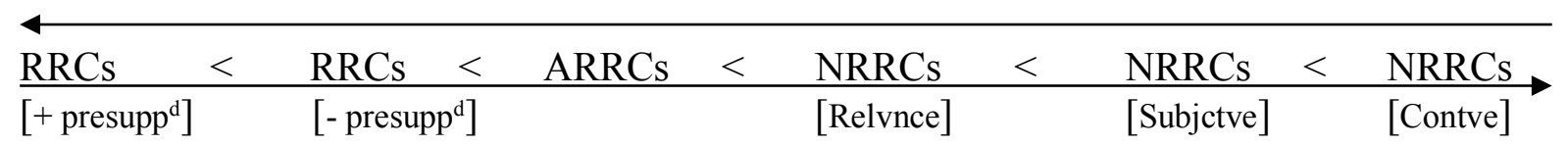

Figure 1

Placement of each of the six subtypes of relative clauses examined along the 'BackgroundForeground' axis at the level of discourse

\footnotetext{
24 As far as this criterion is concerned, Malan (1999: 23-27) amongst others, points out that it is not in fact a reliable condition whether in actual writing or in speech, since there are instances where no punctuation or pausing occurs to separate a NRRC, or where punctuation in the written form occurs for reasons other than simply separating a NRRC from its framing clause. However, in the first type of case at least, the criterion may be exploited 'proactively', by actually inserting a possible set of two commas or pauses, and assessing the effects; and in the latter, where the effect of punctuation is neutralised, it will be the preponderant weight of the results yielded by the other heuristic criteria at issue that will clinch the classification.
} 
Now, as pointed out earlier (see the analysis of example (32) above), a given NRRC may manifest in context more than one discourse status at the same time. When this occurs, there is always a relative dominance relation holding between or amongst the statuses concerned. This may be captured via the following scale. Starting from the right-hand pole in Figure 1, this scale is reflected in the reverse relative order of the positions occupied by these subtypes of NRRC in the former scale:

$$
\text { Continuative }>\text { Subjective }>\text { Relevance }
$$

Figure 2

Scale of relative dominance of simultaneous discourse statuses that may be manifested in context by a given NRRC

\section{CONCLUSIONS}

What we have seen in the above discussion is that, in terms of their contribution to discourse, there is a clear continuum or cline (represented by the scale put forward in Figure 1) characterizing the range of English relative clause subtypes examined in this article. Presupposed RRCs occupy the leftmost pole, that of 'Background', in terms of the intended degree of attention-focusing on the content of the relative assumed by the speaker or writer. Located at the extreme opposite pole on the scale are 'Continuative' NRRCs: these actually serve to advance the discourse created upstream via the occurrence of the host clause (as well as via any preceding utterances, of course). Continuatives are the least syntactically dependent of the subtypes of relative clause at issue. They invariably occur as quasi-autonomous predications, following, i.e. not interpolated within, their host-containing clause; this is unlike what may be the case with Subjective or Relevance NRRCs, where separated encapsulation both within the matrix clause and occurrence in rightward position are possible.

ARRCs fulfil a transitional role. On the one hand, they exhibit properties of RRCs, being integrated within a noun phrase and modifying - in terms of elaboration only - the noun head of their containing NP. On the other hand, they also possess a key feature of NRRCs, namely the ability to introduce discourse-new and on occasion, hearer-new information relevant to the ongoing construction of a given discourse. See Figure 1 in this regard.

As we have seen in $\S 3$, RRCs may or may not be presupposed, and their containing NPs can be definite or indefinite in character. The presupposed/non-presupposed distinction is orthogonal to the definite/indefinite one, since RRCs may be presupposed but indefinite, as in examples (11) and (12), presupposed and definite, as in (23), (26a), (27a), (28a) and (29), non-presupposed and indefinite, as in (5b), or non-presupposed but definite (see (19)). ARRCs, on the other hand, are most frequently both indefinite and (of course) nonpresupposed (see (1), (13)-(15) and (22)). There are, of course, certain mutual affinities: for example, between presupposed RRCs and definite containing NPs, and between ARRCs and indefinite ones, while non-presupposed RRCs tend to occur within both definite and indefinite NPs equally readily. Integrated RCs, whether RRCs or ARRCs, may perform a variety of specific discourse functions, as we saw in $\S 4.1$.

The structural properties of the various subtypes of RC we have examined reflect and underpin their particular discourse functionality: ARRCs and RRCs attach to a lexical category (their containing NP's head noun), either in order simply to elaborate its denotatum (ARRCs) or to set up a narrower denotational subcategory within it (RRCs). In both cases, the $\mathrm{RC}$ at issue forms a constituent with the relevant head noun. This syntactic structure reflects the semantic property of RRCs, which correspond in this respect to complex predicates. At 
the same time, this more restricted predicate will exclude a range of other potential referents which do not possess this more specific property. As we have seen (in §2.2), integrated relatives may have a wider range of relativisers (relative markers or relative pronouns) as possible clause introducers. The availability of the RMs that and $\varnothing$ here (each subtype possessing its own distributional constraints) is due to the fact that integrated relatives manifest a far greater degree of grammatico-semantic cohesion with their host than do NRRCs.

NRRCs, on the other hand, have a phrasal or clausal category as their host unit, and require it to have independent reference with regard to the content of the relative clause itself. As shown in $\S 2.2$ and $\S 4.2$, this means that they tend to accept only relative pronouns as clause introducers. As such, unlike integrated relative clauses, NRRCs constitute fullyfledged discourse units which in this capacity affect the discourse being constructed via the main clause in certain specific ways (see $\$ 4.2$ ).

Author's address:

Laboratoire CLLE-ERSS,

Maison de la Recherche,

Université de Toulouse-Jean Jaurès,

5, Allée Antonio Machado,

31058 Toulouse Cedex 9,

France

E-mail:francis.cornish@univ-tlse2.fr 


\section{REFERENCES}

Aarts, Bas. 2013. English syntax and argumentation, $4^{\text {th }}$ edn. Basingstoke: Palgrave Macmillan.

Arkoh, Ruby \& Lisa Matthewson. 2013. A familiar definite article in Akan. Lingua 123, 130.

Bache, Carl \& Leif Kvistgaard Jakobsen. 1980. On the distinction between restrictive and non-restrictive relative clauses in modern English. Lingua 52, 243-267.

Benveniste, Emile. 1966. Problèmes de linguistique générale. Paris: Gallimard.

Bhat, D.N.S. 2004. Pronouns. Oxford \& New York: Oxford University Press.

Biber, Douglas, Stig Johansson, Geoffrey Leech, Susan Conrad \& Edward Finegan. 1999. Grammar of spoken and written English. London: Longman.

Chierchia, Gennaro \& Sally McConnell-Ginet. 1990. Meaning and grammar. Cambridge Mass. \& London: MIT Press.

Cornish, Francis. 2009. Inter-sentential anaphora and coherence relations in discourse: A perfect match. Language Sciences 31(5), 572-592.

Cornish, Francis \& Anne Salazar Orvig. 2016. A critical look at the notion 'pro-form': Evidence from indexical markers, spoken discourse and (French) child language. Language Sciences 54, 58-76.

Dehé, Nicole. 2014. Parentheticals in spoken English. Cambridge \& New York: Cambridge University Press.

Del Gobbo, Francesca. 2003. Appositives and quantification. U. Penn Working Papers in Linguistics, vol. 9.1, 73-88.

Denison, David \& Marianne Hundt. 2013. Defining relatives. Journal of English Linguistics 41(2), 135-167.

Depraetere, Ilse. 1996. Foregrounding in English relative clauses. Linguistics 34, 699-731.

Dik, Simon C. 1997. The theory of Functional Grammar, Part II: Complex and derived constructions. Berlin \& New York: Mouton de Gruyter.

Emonds, Joseph. 1979. Appositive relatives have no properties. Linguistic Inquiry 10(2), 211-243.

Erteschik-Shir, Nomi. 2007. Information structure. The syntax-discourse interface. Oxford \& New York: Oxford University Press.

Fabb, Nigel. 1990. The difference between English restrictive and non-restrictive relative clauses. Journal of Linguistics 26, 57-78.

Fox, Barbara \& Sandra A. Thompson. 1990. A discourse explanation of the grammar of relative clauses in English conversation. Language 66(2), 297-316.

'The Great American Sandwich': a recorded conversation that formed part of the SSRCfunded project HR5152, The Syntax of Scottish English (1977-1980).

Hannay, Mike \& Evelien Keizer. 2005. A discourse treatment of English non-restrictive nominal appositions in Functional Discourse Grammar. In J. Lachlan Mackenzie \& María de los Ángeles Gómez-González (eds.), Studies in Functional Discourse Grammar, 159-194. Bern: Peter Lang.

Huddleston, Rodney \& Geoffrey K. Pullum. 2002. The Cambridge grammar of the English language. Cambridge: Cambridge University Press.

Jacobson, Pauline. 1989. Issues and results in syntactic theory. Ms, Program in Linguistics and Cognitive Science, Brown University.

Jaggar, Philip. J. 1998. Restrictive vs. non-restrictive relative clauses in Hausa: Where morphosyntax and semantics meet. Studies in African Linguistics 27(2), 199-238.

Jespersen, Otto. 1927. A Modern English Grammar on Historical Principles, Part III Syntax ( $2^{\text {nd }}$ volume). London: Allen \& Unwin/Copenhagen: Munksgaard. 
Keizer, Evelien. 2012. English proforms in Functional Discourse Grammar. Language Sciences 34(4), 400-420.

Larreya, Pierre \& Claude Rivière. 2010. Grammaire explicative de l'anglais, 4th edn. Paris: Pearson Education France.

Loock, Rudy. 2007. Appositive relative clauses and their functions in discourse. Journal of Pragmatics 39, 336-362.

Loock, Rudy. 2010. Appositive Relative Clauses in English. Amsterdam \& Philadelphia: John Benjamins.

Lyons, John. 1977. Semantics, vol. 2. Cambridge: Cambridge University Press.

Malan, Naomi. 1999. La proposition relative en anglais contemporain. Une approche pragmatique. Gap \& Paris: Ophrys.

McCawley, James. D. 1981. The syntax and semantics of English relative clauses. Lingua 53, 99-149.

McCloskey, James. 1979. Model-theoretic semantics and transformational grammar. Dordrecht: Reidel.

Miller, Jim. 2008. An introduction to English syntax, 2nd edn. Edinburgh: Edinburgh University Press.

Miller, Jim and M.M. Jocelyne Fernandez-Vest. 2006. Spoken and written language. In Giuliano Bernini \& Marcia L. Schwarz (eds.), Pragmatic organization of discourse in the languages of Europe, 9-64. Berlin \& New York: Mouton de Gruyter.

Osam, E. Kweku. 2003. An introduction to the verbal and multi-verbal system of Akan. In D. Beermann \& L. Hellan (eds.), Proceedings of the workshop on multi-verb constructions. Trondheim Summer School, 2003. http://edvarda.hf.ntnu.no/ling/tross/ $<$ http://edvarda.hf.ntnu.no/ling/tross/>

$\mathrm{Pu}$, Ming-Ming. 2007. The distribution of relative clauses in Chinese discourse. Discourse Processes 43(1), 25-53.

Quirk, Randolph. 1957. Relative clauses in educated spoken English. English Studies 38, 97109.

Quirk, Randolph, Sidney Greenbaum, Geoffrey Leech \& Jan Svartvik. 1985. A Comprehensive Grammar of the English Language. London: Longman.

Rydén, Mats. 1974. On notional relations in the relative clause complex. English Studies 55, 542-545.

Sag, Ivan. A. 1997. English relative clause constructions. Journal of Linguistics 33(2), 431483.

Schachter, Paul. 1973. Focus and relativization. Language 49(1), 19-46.

Sigley, Robert. 1997. Choosing your relatives: Relative clauses in New Zealand English. Victoria: Victoria University dissertation (cited in Denison \& Hundt 2013).

Van der Auwera, Johan. 1985. Relative that - a centennial dispute. Journal of Linguistics 21, 149-179. 